\title{
Evolutionary framework of hierarchy of effects models: exploring relevance in the shifting of customer path
}

Rishi Chakravarty

Department of Management, Krishna Kanta Handiqui State Open University, Guwahati, India and Department of Management, Assam Down Town University, Guwahati, India, and

\section{Nripendra Narayan Sarma}

Department of Management, Krishna Kanta Handiqui State Open University, Guwahati, India
Hierarchy of effects models

Received 1 October 2020 Revised 7 January 2021 Accepted 28 February 2021

\begin{abstract}
Purpose - The hierarchies of effects models have been perpetually updated across different time period. Ever since the evolution of the primary customer path indicated through the Attention, Interest, Desire, Action model in the 1900s, the hierarchical frameworks have witnessed a significant transformation in context to the present age of Web connectivity. Therefore, the purpose of this study is to understand the transformation in the hierarchy of effects models in the age of connectivity.

Design/methodology/approach - This paper is conceptual in nature and an attempt to provide an overall view of the shifting dimension in the customer path as indicated in the various hierarchies of effects models since evolution up to the age of digitalisation.

Findings - It is observed that in the age of connectivity customer loyalty is expressed in terms of brand advocacy rather than repurchase, and that the customer path has been redefined. This seems pertinent because of the swift exchange of information that occurs among the online customer communities.

Originality/value - This paper identifies a need to provide a contemporary outlook to the customer path in the age of internet connectivity.
\end{abstract}

Keywords Hierarchy of effects, Customer path, Internet connectivity, Brand advocacy, Online customer communities

Paper type Conceptual paper

\section{Introduction}

The digital disruptions have significantly affected the hierarchy models of advertising effects and have generated a paradigm shift in the way customers think and make decisions. The hierarchy models of communication effects prevalent since the 1900s (Barry and Howard, 1990)

(C) Rishi Chakravarty and Nripendra Narayan Sarma. Published in Vilakshan - XIMB Journal of Management. Published by Emerald Publishing Limited. This article is published under the Creative Commons Attribution (CC BY 4.0) licence. Anyone may reproduce, distribute, translate and create derivative works of this article (for both commercial and non-commercial purposes), subject to full attribution to the original publication and authors. The full terms of this licence maybe seen at http:// creativecommons.org/licences/by/4.0/legalcode

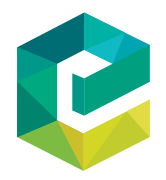

Vilakshan - XIMB Journal of Management Vol. 19 No. 1, 2022 
need a reoriented look. Traditionally, marketing was primarily focused on segmenting, which is a process of dividing the entire market into homogeneous groups based on geographic, demographic, psychographic and behavioural profiles, and thereafter targeting the customers in each group based on their needs. However, the emergence of the digital economy has provided a new dimension in the form of online communities of customers who are the contemporary target groups for marketers (Kotler et al., 2016). Such online customer communities are a conglomerate of acquaintances connected with one another in the digital world and are sensitive to any sort of irrelevant and manipulative product or service related information. Over the years, there has been a need-based transformation in the way companies communicate with its new breed of emerging young customers who are connected with one another on a virtual platform. The digital economy has further enhanced an undisrupted flow of information amongst the online customer communities that has led to the delivery of transparent information about products and services from the marketers, so that they can transform a customer into a loyal brand advocate (Kotler et al., 2016). Customers today are better informed about products through the exchange of information that happen in those online communities. However, understanding the customer is a complex process because of the regular shift in their tastes and preferences which has led to constant research on the understanding as well as developing frameworks to describe the customer path, as it is evident from previous literature related on the different hierarchical models of advertising effects (Barry, 1987; Barry and Howard, 1990). Also, according to Barry, (1987), Barry and Howard (1990), the first traditional model of measuring advertising effectiveness was introduced by E. St. Elmo Lewis in the year 1898 which is popularly known as Attention-Interest-Desire (AID). Thereafter several hierarchical models were developed by researchers in their inquisitiveness to understand the transformation that took place in the behavioural pattern of customers due to advertisements (Smith and Swinyard, 1983; Cobb and Hoyer, 1985). However, with the development in the area of information and technology, the hierarchical models of advertising effects underwent significant transformation. Contrary to the earlier models, which were more oriented to gain the attention of the customers, the hierarchical models due to the digital transformation are more inclined towards adding value to the brand so as to gain brand advocates (Kotler et al., 2016). In addition to generating awareness about products and inducing purchases, the new age marketing communication concentrate on building brand value and customer loyalty (Wijaya, 2012). This paper therefore is an attempt to understand the changing dimension in the hierarchy of effect models of advertising through the traditional, modern and the digital era that has eventually witnessed a paradigm shift towards the development of a new customer path. The objectives of this research work have been formulated as under:

- To study the emerging trends in the literature regarding hierarchy models of communication.

- To develop an evolutionary framework of the hierarchy of effects models through phases, namely, traditional phase, pre-connectivity phase and digital phase.

- To comment on the relevance of hierarchy of communication effects models in the shifting of customer path.

\section{Traditional phase}

The hierarchy models of communication effects have gone through several modifications ever since the first and most widely used AID model which was an effective framework to describe the customer path (Wijaya, 2011). The model was primarily focused on enhancing sales without much concentration on the need of the customer. However, later in the year 
1900 the model was modified by Lewis and included action as an essential step in the path that gained popularity as Attention $\rightarrow$ Interest $\rightarrow$ Desire $\rightarrow$ Action or AIDA (Barry T.E., 1987; Barry, T.E. and Howard, D.J., 1990).

The hierarchy models of communication in the pre-connectivity period can be subdivided into traditional and modern phase (Chakravarty and Sarma, 2018). Over the years, several researchers have modified the AIDA model and interpreted in their own ways. It is however observed that in most of the redefined models - attention, interest and desire were considered because the prime objective of communication through advertising was to gain the attention of the customers and create an interest in the advertised products (Barry T.E., 1987; Barry, T.E. and Howard, D.J., 1990). Even though all the traditional hierarchical models were aimed at enhancing sales yet researchers also recognized that customer satisfaction was an important element in the path. Therefore, in the year 1911, Arthur F. Sheldon had incorporated "Satisfaction" as the last element in his model which was known as Attention $\rightarrow$ Interest $\rightarrow$ Desire $\rightarrow$ Action $\rightarrow$ Satisfaction or AIDAS (Chakravarty and Sarma, 2018 adapted from Barry, 1987; Barry and Howard, 1990). Thereafter in the year 1915, Samuel R. Hall had felt that customers would purchase a product only when they are confident and convinced to the advertising message and led to the development of a framework with the addition of conviction. Hence, a new framework

Attention $\rightarrow$ Interest $\rightarrow$ Confidence $\rightarrow$ Conviction $\rightarrow$ Action or AICCA was developed (Chakravarty and Sarma, 2018 adapted from Barry, 1987; Barry and Howard, 1990).

Table 1 highlights the traditional phase of the Hierarchy Models of communication as adapted from the works of (Barry, 1987; Barry and Howard, 1990).

Understanding the customer is a complex process. Whether a customer would follow every path in the different models (highlighted in Table 1) while making a decision is yet to be explored. However, contrary to the customer path as indicated in the traditional frameworks (Table 1) inclining towards sales enhancement, the models developed thereafter in the modern phase were more concentrated on measuring the effectiveness of advertising messages. In this context, the works of (Lavidge and Steiner, 1961; Colley, 1961) could be considered as significant, as they are widely acknowledged in modern advertising. Lavidge and Steiner (1961) had proposed a more elaborative customer path through a six stage framework for measuring advertising effectiveness from generating awareness to ultimate purchase (AwarenessKnowledge-Liking-Preference-Conviction-Purchase). (Colley, 1961) had pioneered the ACCA model (Awareness-Comprehension-Conviction-Action) in his work "Defining Advertising Goals for Measured Advertising Results (DAGMAR)". According to Colley (1961), in the first stage of the customer path advertising generates awareness among the audiences about the products that is advertised. In the next stage, the audiences are able to comprehend the message that an advertisement generates. In the third stage of the path, they are convinced about the reliability of the advertising message and which persuades them to take an action through purchase.

\section{Pre-connectivity phase}

The framework by Lavidge and Steiner (1961) captured the emerging trend in the modern context of wider penetration of print media and advent of audio video media vehicles as indicated in Figure 1.

The Advertising Research Foundation in 1961 had identified and developed a five step hierarchical model of Exposure $\rightarrow$ Perception $\rightarrow$ Knowledge $\rightarrow$ Attitude $\rightarrow$ Action (Chakravarty and Sarma, 2018). The customer path as reflected in the hierarchical models in pre connectivity phase in Table 2 .
Hierarchy of effects models 


\begin{tabular}{|c|c|c|c|}
\hline \multirow{2}{*}{$\begin{array}{l}\text { XJM } \\
19,1\end{array}$} & & & \\
\hline & Year & Model & $\begin{array}{l}\text { Author/ } \\
\text { developer }\end{array}$ \\
\hline \multirow{12}{*}{62} & 1898 & Attention, Interest, Desire (AID) & E. St. Elmo Lewis \\
\hline & Circa 1900 & $\begin{array}{l}\text { Attention, Interest, Desire, Action } \\
\text { (AIDA) }\end{array}$ & E. St. Elmo Lewis \\
\hline & 1910 & $\begin{array}{l}\text { Attention, Interest, Conviction, } \\
\text { Action (AICA) }\end{array}$ & Printer's Ink \\
\hline & 1911 & $\begin{array}{l}\text { Attention, Interest, Desire, Action, } \\
\text { Satisfaction (AIDAS) }\end{array}$ & $\begin{array}{l}\text { Arthur F. } \\
\text { Sheldon }\end{array}$ \\
\hline & 1915 & $\begin{array}{l}\text { Attention, Interest, Confidence, } \\
\text { Conviction, Action (AICCA) }\end{array}$ & Samuel R. Hall \\
\hline & 1920 & $\begin{array}{l}\text { Attracting Attention, Creating } \\
\text { Desire, Removing }\end{array}$ & $\begin{array}{l}\text { West Coast Life } \\
\text { Insurance } \\
\text { Company }\end{array}$ \\
\hline & & $\begin{array}{l}\text { Inhibitions, Inspiring Confidence, } \\
\text { Impelling to Action (ADICA) }\end{array}$ & \\
\hline & 1921 & $\begin{array}{l}\text { Attention, Interest, Desire, Caution, } \\
\text { Action (AIDCA) }\end{array}$ & $\begin{array}{l}\text { Robert E. } \\
\text { Ramsay }\end{array}$ \\
\hline & 1922 & $\begin{array}{l}\text { Attention, Interest, Judgement, } \\
\text { Action (AIJA) }\end{array}$ & $\begin{array}{l}\text { Alexander } \\
\text { Osborn }\end{array}$ \\
\hline & 1923 & $\begin{array}{l}\text { Seen, Remembered, Believed, Read, } \\
\text { Acted Upon (SRBRA) }\end{array}$ & Daniel Starch \\
\hline & 1938 & $\begin{array}{l}\text { Attention, Interest, Desire (Want), } \\
\text { Conviction (Solution), Purchase, } \\
\text { Satisfaction (AID(W)C(S)PS) }\end{array}$ & $\begin{array}{l}\text { Edward K. } \\
\text { Strong, Jr }\end{array}$ \\
\hline & 1940 & $\begin{array}{l}\text { Attention, Interest, Desire, } \\
\text { Conviction, Action (AIDCA) }\end{array}$ & Clyde Bedell \\
\hline Tab & 1956 & $\begin{array}{l}\text { Attention, Interest, Desire, Memory, } \\
\text { Action (AIDMA) }\end{array}$ & Merill DeVoe \\
\hline
\end{tabular}
the hierarchy models of communication

Sources: Chakravarty and Sarma (2018) adapted from Barry T.E. (1987); Barry, T.E. and Howard, D.J. (1990)

\section{Digital phase}

All the previous hierarchical models have been developed during the pre-connectivity period when the unlimited capability of the internet was still unexplored. The digital disruption created by the evolution of the internet has made both researchers and management practitioners to look at the hierarchical framework from a different perspective. The internet has significantly influenced the society and transformed the process of communication (Cappo, 2003). The emergence of the social media has provided a new dimension in the form of online communities of customers who are the contemporary target groups for marketers. The customer paths demonstrated in the previous hierarchical models are not sufficient in this current age of digitalization that has transformed the way people socialize and communicate with one another (Wijaya, 2012). It is observed that the customer path in the previous hierarchical models did not indicate follow up action which is essential to understand the level of satisfaction of the customers and measure their post-purchase behaviour. To this have commented that the previous hierarchy of effect models and also the one proposed by (Lavidge and Steiner, 1961; Colley, 1961) had illustrated a suitable customer path that might end in ultimate purchase of the advertised product (Weilbacher, 2001). However, there was a lack of any empirical evidence to justify that the customers actually passes through each stage before taking a decision. Such gaps identified in the literature had 


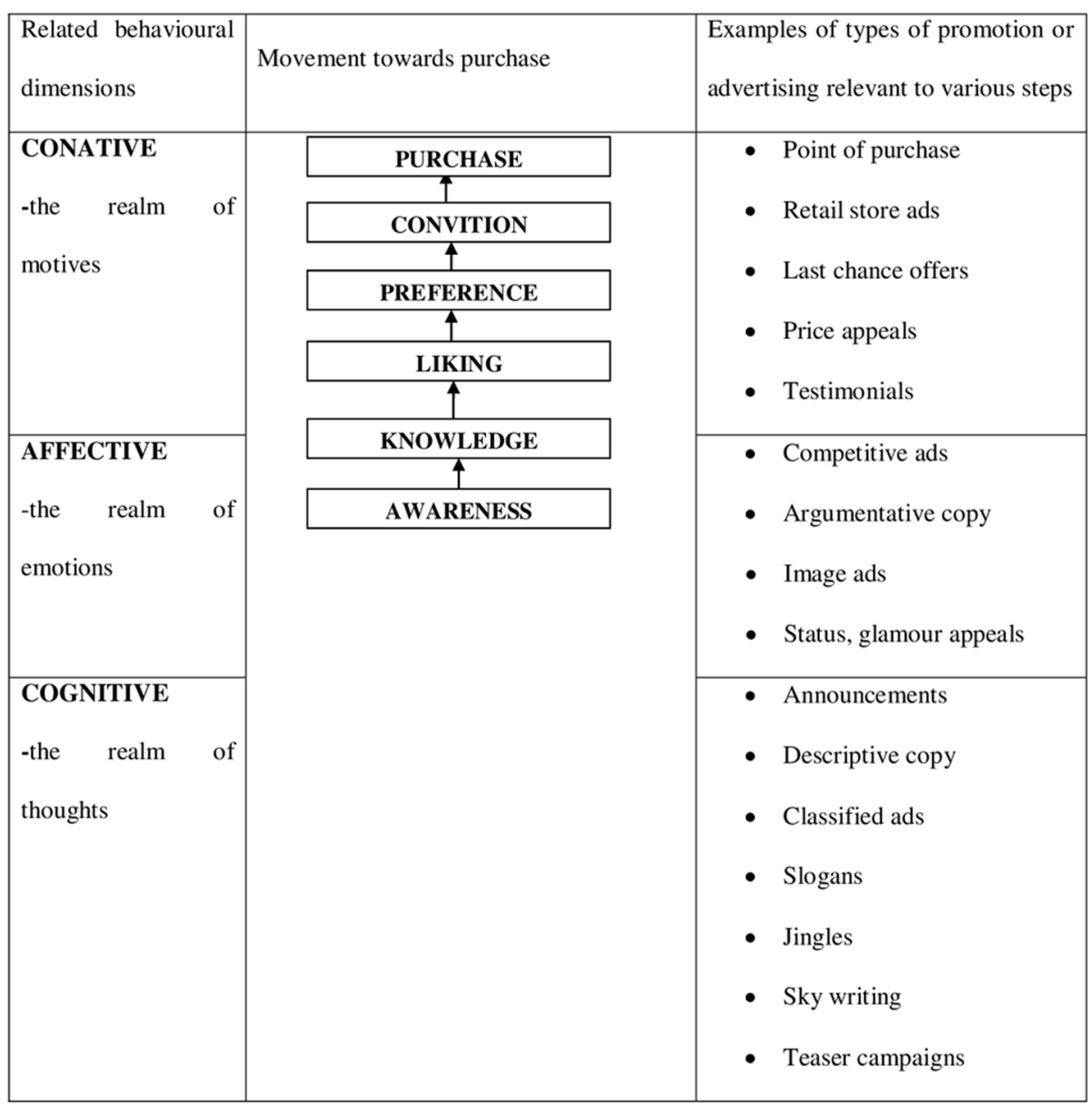

Sources: Chakravarty and Sarma (2018) adapted from Lavidge and Steiner (1961); Barry and Howard (1990)

necessitated the development of an evolutionary framework of hierarchy of effects models. Considering that the customer path as indicated in the AIDA framework was the earliest and widely used in several studies related to advertising and a popular model used by practitioners therefore the authors of this study have adopted this as the base model.

In the current context, information travels at the speed of light and customers neither have the time to evaluate the advertising messages in the pre-purchase stage nor the advertised products at the post-purchase stage. They exhibit a tendency to rely on online references for advice. Online communities exchange the information about products that are advertised online and thereafter arrive at a decision. It prompts the companies to provide information that are reliable and worthy of being considered by the communities. This highlights the importance of updating the customer path in this connectivity period. In this age of internet when people are socially connected with one another, the role of advertising has extended
Hierarchy of effects models

63

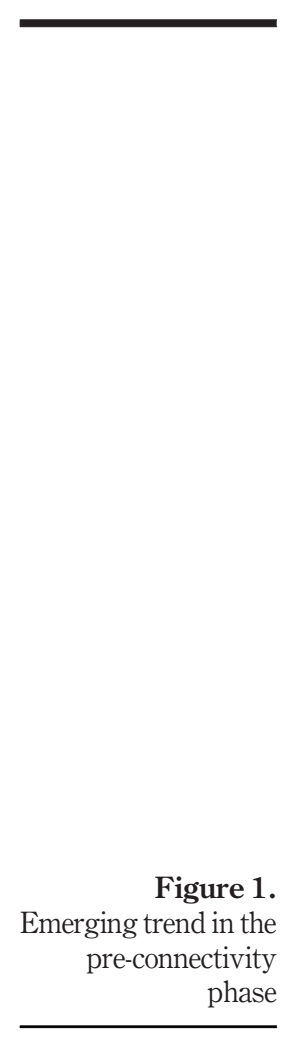

Emerging trend in the pre-connectivity phase 


\begin{tabular}{lll}
\hline Year & Author/developer & Model \\
\hline 1961 & Robert J. Lavidge and Gary A. & Awareness, Knowledge, Liking, Preference, Conviction, \\
& Steiner & Purchase \\
1961 & Russell H. Colley & Awareness, Comprehension, Conviction, Action (ACCA) \\
1961 & Advertising Research & Exposure, Perception, Communication (Knowledge), \\
& Foundation & Communication (Attitude), Action (EPC(K)C(A)A) \\
1962 & Harry D. Wolfe, James K. & Awareness, Acceptance, Preference, Intention, \\
& Brown and G. Clerk & Provocation of Sale (AAPIS) \\
& Thompson &
\end{tabular}

1962

1964

1967

1969

1969

1969

1971

1971

1974

1975

1980

1981

1982

1982

\section{Table 2.}

Contemporary

Hierarchical models of communication in the modern path
Ivan L. Preston

\section{Everett M. Rogers}

Leo V. Aspinwall

Sandage and Fryburger

David A. Schwartz

John Howard and Jagdish

Sheth

Wiliam J. McGuire

Thomas S. Robertson

Kenneth A. Longman

Andrew S.C. Ehrenberg

Morris B. Holbrook

Richard Vaughn

Michael L. Rothschild and William C. Gaidis

Robert E. Smith and William

R. Swinyard

Ivan L. Preston
Awareness, Interest, Evaluation, Trial, Adoption (AIETA)

Acceptance, Preference, Insistence (API)

Exposure, Preference, Integration, Action (EPIA)

Exposure, Attention, Retention, Attitude, Change,

Purchase (EARACP)

Attention, Comprehension, Attitude, Intention, Purchase (ACAIP)

Presentation, Attention, Comprehension, Yeilding,

Retention, Behaviour (PACYRB)

Awareness, comprehension, Attitude, Legitimation, Trial, Adoption (ACALTA)

Exposure, Attention, Perception, Comprehension, Belief, Motivation, Action (EAPCBMA)

Awareness, Trial, Reinforcement (ATR)

Attention, Perception, Memory, Attitude, Intention (APMAI)

Stated that "thinking model"-the traditional hierarchy model of cognition, affect, conation-not adequate; added three additional models in different sequencing, e.g. affectcognition-conation; conation-cognition-affect; Conationaffect-cognition

For low involvement purchases; advertising acts as stimuli for awareness and knowledge; leads to trial; product becomes stimulus, satisfaction may lead to increased probability of repeat purchasing behaviour The learning hierarchy may not be appropriate for low order belief and affect; suggest three models: traditional of cognition-affect-commitment; low involvement of cognition-trial-affect-commitment; and brand switching of cognition-trial-trial-trial

Presents more comprehensive consumer information processing model stating lack of this in previous models: Distribution, Vehicle Exposure, Ad Exposure, Ad

Awareness, Ad Elements Awareness, Association Evaluation, Product Perception, Integrated Perception, Product Evaluation, Prior Evaluation, Integrated Evaluation, Product

Stimulation, Prior Stimulation, Integrated Stimulation, Action; states traditional hierarchy valid in spite of low involvement theory

Defends traditional hierarchy models and adds to the

Association Model of 1982 with: Search, Search

Perception, Search Evaluation, Search Stimulation, Trial, Trial Perception, Trial Stimulation, Adoption, Adoption 


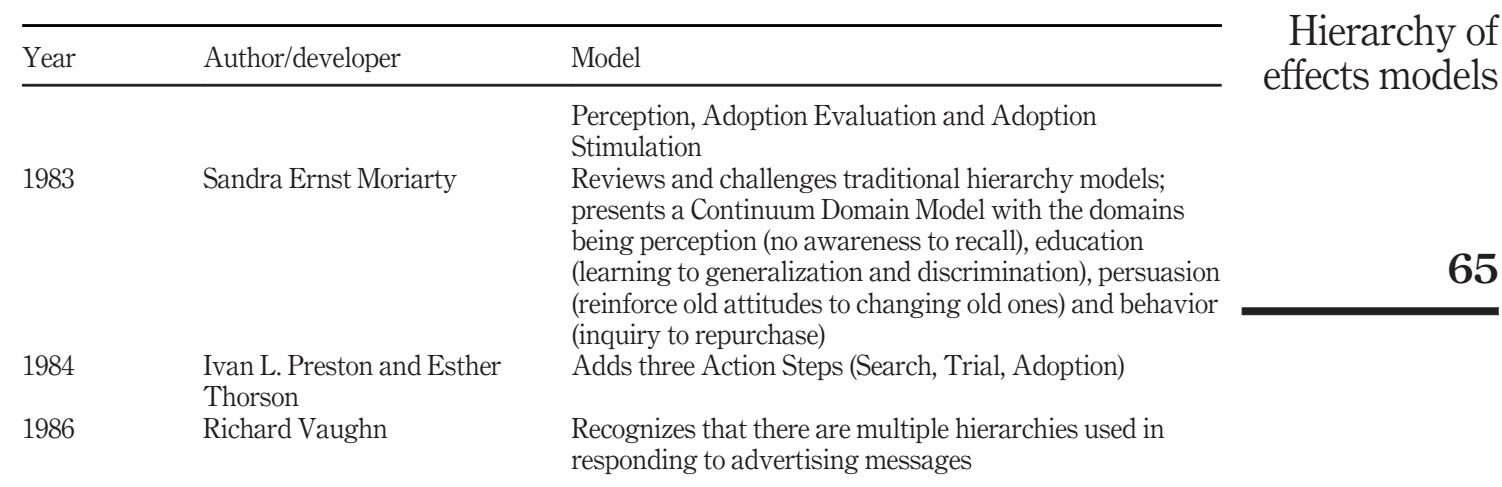

Sources: Chakravarty and Sarma (2018) adapted from Barry T.E. (1987); Barry, T.E. and Howard, D.J. (1990)

Table 2.

beyond the boundaries of enhanced purchase alone and should be more focused on customers' preference and brand development (Wijaya, 2011). In this context, a new customer path along a hierarchy has been developed as indicated in Figure 2:

The above model is an extension of the AIDA hierarchy where the author has included S (Search), L (Like/Dislike), S (Share) and L (Love/Hate) which indicates that after generating interest in the advertised product, the customer will search for information about the product from various sources. In context to online advertising, such sources could be the online community of customers who may exchange their opinions about the products. The stages after action denotes the post purchase effects of the customer based on his level of satisfaction. However, the author has not clearly indicated whether the customer will follow the entire path in the proposed hierarchy. According to Kotler et al. (2016), the digital age has provided a shift in the customer path and it is indicated through the Five A's framework as shown in Figure 3.

In this connectivity age, the path from awareness to advocacy need not be in a sequence as indicated in the above figure. Understanding the buyer attitude is a complex process because it is a "learned predisposition" that makes a buyer to behave either in a favourable or in an unfavourable manner towards an advertisement (Schiffman and Kanuk, 2004; Assael, 2008). Also if the advertisement is able to generate a favourable impression in the mind of the customer about the advertised product the customer may directly take a decision and may skip the appeal towards a purchase decision. In connectivity era, customer loyalty is defined as the willingness of the customer to generate strong recommendation in favour of the advertised brand or the product (Kotler et al., 2016). Thus a satisfied customer may resort to brand advocacy and recommend it to others. Derek Rucker in Kotler et al. (2016) had offered the 4A's of hierarchy of effect model as a modification to the already existing AIDA framework as indicated in Figure 4.

According to this model, the customers learn and become aware about the products through the communication generated by the advertisements. They develop liking and

\section{Attention $\longrightarrow$ Interest $\longrightarrow$ Search $\longrightarrow$ Desire $\longrightarrow$ Action $\longrightarrow$ Like/Dislike $\longrightarrow$ Share $\longrightarrow$ Love/Hate}

Figure 2.

Source: Wijaya (2011) 


\section{$\mathrm{XJM}$ \\ 19,1}

Figure 3.

Shifting customer path in digital era
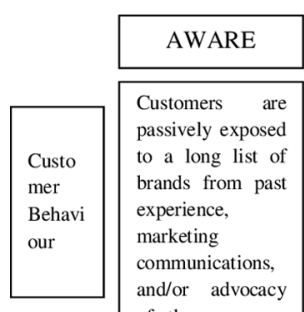

Customers are passively exposed to a long list of brands from past experience,

marketing communications, and/or advocacy of others

\begin{tabular}{|l|l|}
\hline $\begin{array}{l}\text { Possi } \\
\text { ble } \\
\text { custo } \\
\text { mer } \\
\text { touch } \\
\text { points }\end{array}$ & $\begin{array}{l}\text { 1. Learn about a } \\
\text { brand from others } \\
\text { 2. Inadvertently } \\
\text { exposed to a } \\
\text { brand advertising } \\
\text { 3. Recall past } \\
\text { experience }\end{array}$ \\
\hline
\end{tabular}
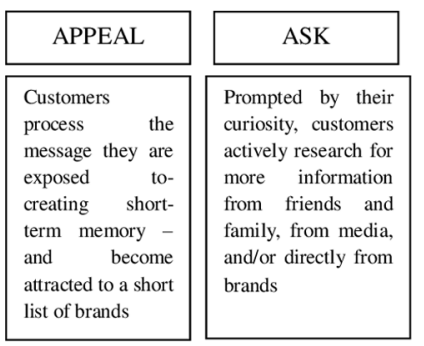

1. Become
attracted to brands

2. Create a

consideration set

of brands
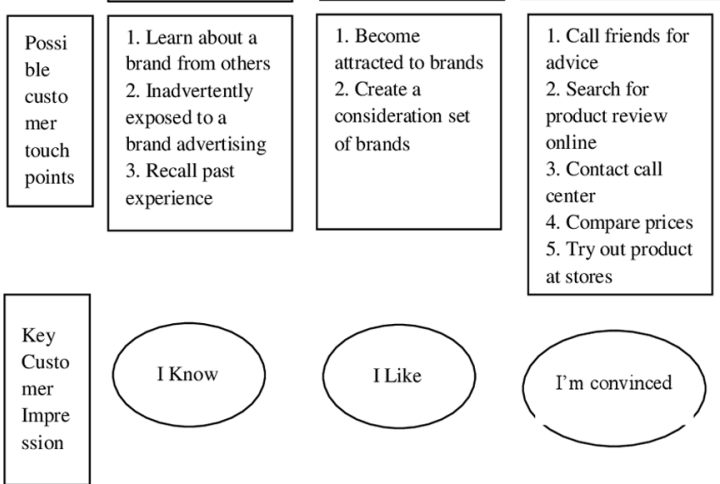

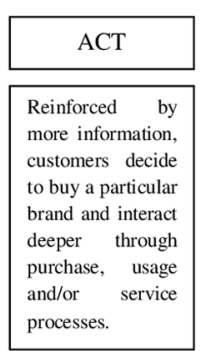

ADVOCATE

Over time, customers may develop a sense of strong loyalty to the brand, which is reflected in the retention, repurchase, and ultimately advocacy to others.

1. Buy in-store or online

2. Use the product for the first time

3. Complain about the problem

4. Get the service

1. Keep using the brand

2. Repurchase the brand

3. Recommend the brands to

others
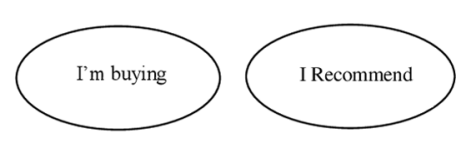

Source: Kotler et al. (2016)

disliking towards the advertised products which shape their attitude and induce them to act by either accepting or rejecting the advertised product. Thereafter, the act again stage has been added in order to understand the post purchase effect.

The hierarchical models developed during the traditional phase were inclined towards enhancing sales while those developed during the pre-connectivity phase concentrated more on the attitude formation of the customer and the models developed during the digital phase were focused on the behavioural aspect of the customers either in the form of repurchasing the advertised brand or by being loyal brand advocates. Thus an evolutionary framework of the hierarchy of effects models has been clearly depicted across the different phase that signifies a transformational shift in the customer path as indicated in Figure 5.

\section{Managerial implications concluding remark and future scope}

Every model from the early part of the previous century till date is relevant in respect of the time when that was propounded. The models could provide insight for a customer path. The new age models have changed to capture the emerging trends. Not only capturing the time specific trends, the hierarchy of communication effect models provides scope for marketers to develop their

Figure 4.

Derek Rucker's $4 \mathrm{~A}$

hierarchy of communication effects

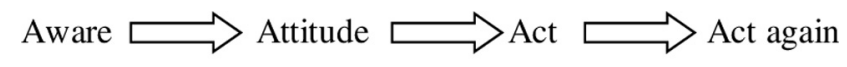

Source: Kotler et al. (2016) 

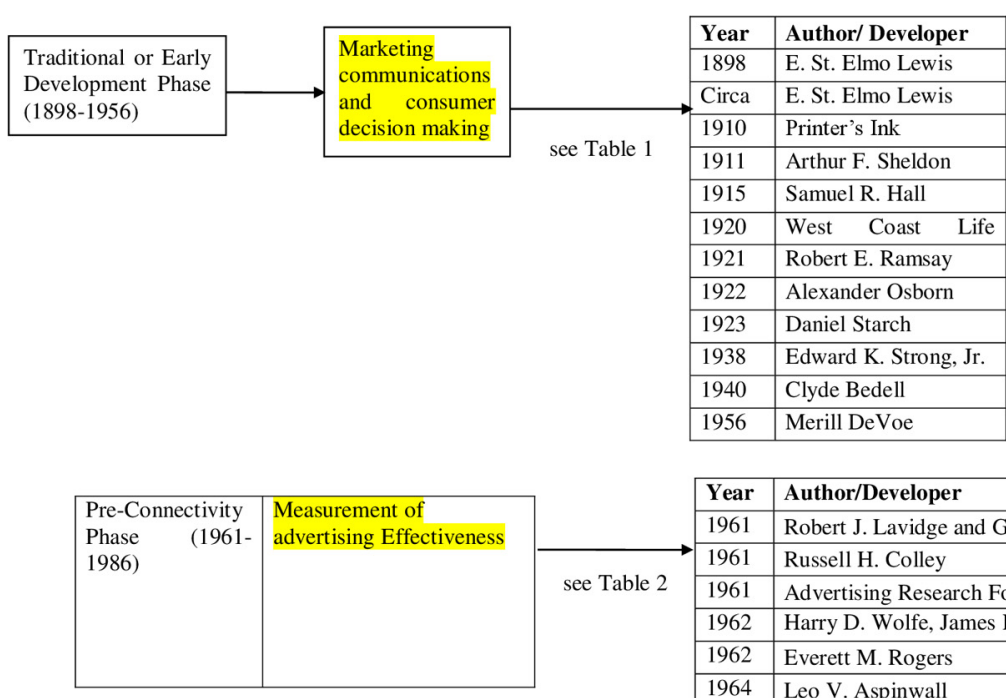

\begin{tabular}{|l|l|l|}
\cline { 2 - 3 } & Year & Author/Developer \\
\cline { 2 - 3 } & 1961 & Robert J. Lavidge and Gary A. Steiner \\
\hline \multirow{3}{*}{ see Table 2} & 1961 & Russell H. Colley \\
\cline { 2 - 3 } & 1961 & Advertising Research Foundation \\
\cline { 2 - 3 } & 1962 & Harry D. Wolfe, James K. Brown and G. \\
\cline { 2 - 3 } & 1962 & Everett M. Rogers \\
\hline 1964 & Leo V. Aspinwall \\
\hline 1967 & Sandage and Fryburger \\
\hline 1969 & David A. Schwartz \\
\hline 1969 & John Howard and Jagdish Sheth \\
\hline 1969 & Wiiliam J. McGuire \\
\hline 1971 & Thomas S. Robertson \\
\hline 1971 & Kenneth A. Longman \\
\hline
\end{tabular}

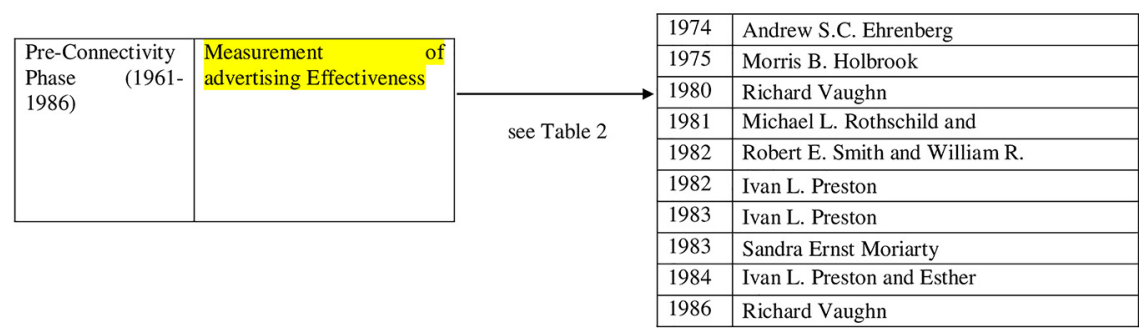

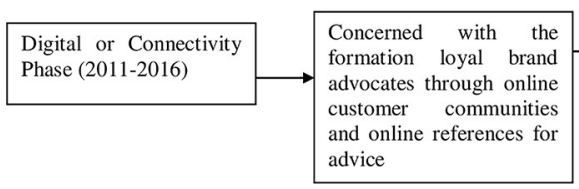

\begin{tabular}{|c|c|c|c|}
\hline & Year & Model & Author \\
\hline \multirow{3}{*}{$\begin{array}{l}\text { see Figure 2, Figure } 3 \\
\text { and Figure } 4\end{array}$} & 2011 & AISDALSLove & Wijaya \\
\hline & 2016 & $5 \mathrm{~A}$ 's & Kotler et al. \\
\hline & 2016 & 4A's & Rucker \\
\hline
\end{tabular}

Hierarchy of effects models

Figure 5.

Evolutionary framework of hierarchy of effects model

advertising strategies to sustain in the respective marketing environment. However, with the growth and development of the internet, the hierarchical models have been updated and new customer path has been developed. Marketers need to be honest and truthful in communicating to the online group of customers as such groups are very much sensitive to misleading information and a wrong message from the marketer may open the door for its competitors to enter. The pioneer advantage and sustaining the same will create the entry barriers for the prospective competitors. 
However, whether the customer will follow the entire path as indicated in the different hierarchy models will have to be further established through investigation as previous researchers did not focus much on this aspect.

\section{References}

Assael, H. (2008), Consumer Behaviour and Marketing Action, Cengage Learning India Private Limited, New Delhi.

Barry, T.E. (1987), "The development of the hierarchy of effects: an historical perspective", Current issues and Research in Advertising, Vol. 10 No. 1/2, pp. 251-295, doi: 10.1080/ 01633392.1987 .10504921$.

Barry, T.E. and Howard, D.J. (1990), "A review and critique of the hierarchy of effects in advertising", International Journal of advertising, Vol. 9 No. 2, pp. 121-135, doi: 10.1080/02650487.1990.11107138.

Cappo, J. (2003), The future of advertising: new media, new clients, new consumers in the post-television age, McGraw-Hill, New York, pp. 189-193.

Chakravarty, R. and Sarma, N.N. (2018), "Hierarchy of effects and consumer buying: findings from literature review", Journal of Open Learning and Research Communication, Vol. 4, pp. $36-56$.

Cobb, C.J. and Hoyer, W.D. (1985). The influence of advertising at the moment of brand choice. Journal of Advertising, Vol. 14 No. 4, pp. 5-27, doi: 10.1080/00913367.1985.10672965.

Colley, R.H. (1961), Defining Advertising Goals for Measured Advertising Results, Association of National Advertisers, New York, NY.

Kotler, P., Kartajaya, H. and Setiawan, I. (2016), Marketing 4.0: Moving from traditional to digital, Wiley India Pvt. Ltd., New Delhi.

Lavidge, R.J. and Steiner, G.A. (1961), "A model for predictive measurements of advertising effectiveness", Journal of marketing, Vol. 25 No. 6, pp. 59-62, doi: 10.1177/002224296102500611.

Schiffman, L.G. and Kanuk, L.L. (2004), Consumer Behaviour, Pearson Education, New Delhi.

Smith, R.E. and Swinyard, W.R. (1983). Attitude-behavior consistency: the impact of product trial versus advertising. Journal of Marketing Research, pp. 257-267, doi: 10.1177/ 002224378302000304 .

Weilbacher, W.M. (2001), "Point of view: does advertising cause a hierarchy of effects?" Journal of Advertising Research, Vol. 41 No. 6, pp. 19-26, doi: 10.2501/JAR-41-6-19-26.

Wijaya, B.S. (2011), "New model of hierarchy of effects in advertising”, ISSIT, Vol 1 No. 1, pp. 5-15.

Wijaya, B.S. (2012), "The development of hierarchy of effects model in advertising”, International Research Journal of Business Studies, Vol. 5 No.1, doi: 10.21632/irjbs.5.1.73-85.

\section{About the authors}

Rishi Chakravarty, Research Scholar, Maniram Dewan School of Management, Krishna Kanta Handiqui State Open University, Assam, India; Assistant Professor, Department of Management, Assam downtown University, Assam, India. Rishi Chakravarty is the corresponding author and can be contacted at: rishi.chakravarty2020@gmail.com

Dr Nripendra Narayan Sarma, Professor and Director, Maniram Dewan School of Management \& Center for Internal Quality Assurance, Krishna Kanta Handiqui State Open University, RAssam, India.Email: nnsarma@kkhsou.in or nripendransarma@gmail.com

For instructions on how to order reprints of this article, please visit our website:

www.emeraldgrouppublishing.com/licensing/reprints.htm

Or contact us for further details: permissions@emeraldinsight.com 